\title{
Applicability of failure strain for the stability evaluation of square pillars in room and pillar mining
}

\author{
GF Napa-García Instituto Tecnológico Vale, Brazil \\ VF Navarro Torres Instituto Tecnológico Vale, Brazil
}

\begin{abstract}
Pillar stability is an active research topic, and is important in the safety evaluation of underground mining projects. Commonly, pillar stability is evaluated using empirical formulations based on specific case studies and rock mass conditions. Numerical modelling could be a very useful tool given its ability to represent a wide range of field situations, as well as material behaviour. However, the evaluation of the safety factor using numerical models may be a challenging task when a large number of runs is required to yield a reliable estimate, e.g. strength reduction or load testing. In this context, a fast and accurate method of measuring pillar safety is desirable. The failure strain proposed by Sakurai (1981) was studied to understand and propose its use when adapted to room and pillar stability by means of numerical modelling. The commercial software package FLAC3D was used to evaluate the continuum mechanics problem. A wide range of parameters involved in the calculation were explored. Results suggest that the failure strain seems to be a promising tool when used correctly. Considerable time saving can be made without losing accuracy.
\end{abstract}

Keywords: safety, pillar stability, numerical modelling, FLAC3D, failure strain

\section{Introduction}

The evaluation of room and pillar (R\&P) stability in mining projects is still an active research topic because of potential failures that may cause safety, cost or environmental impacts. Many factors could influence the stability of R\&P mines, such as pillar and foundations failures, or potential roof instabilities due to beam flexure, or shear failures. The mechanical stability of pillars is critical, because their failure might induce a catastrophic event due to the lack of redundancy associated with this type of failure. According to Idris et al. (2015), a pillar can be defined as the remaining rock mass between two or more underground openings. The mechanical stability of pillars has been evaluated in literature by means of empirical methods (Laubscher 1990; Bullock 2011; Lunder \& Pakalnis 1997; Obert \& Duvall 1967), and by numerical methods (Idris et al. 2015; Gao \& Ge 2016; Corkum \& Board 2016; Navarro Torres et al. 2011; Kortnik 2009; Jaiswal \& Shrivastva 2009; Deng et al. 2003; Pariseau \& Eitani 1981).

Numerical modelling is a powerful design tool because of its ability to incorporate complex material behaviour and model complex geometries. However, these advantages come at high time and computational cost. Hence, the use of efficient techniques to predict design conditions is desired. The critical strain $\varepsilon_{\text {crit }}$ approach proposed by Sakurai (1981), and later used by several authors in order to estimate the stability of underground structures (Sakurai et al. 1993; Sakurai 1997, 1999; Idris et al. 2015; Aydan et al. 1993), offers an attractive solution to this problem. Sakurai's method seems to be appealing because its need to run only one typical stress-strain analysis to obtain a measurement of a stability index in terms of the mobilised strain. In Sakurai's method, the critical strain is defined as the ratio of the uniaxial compressive strength (UCS) to the modulus of deformability (E) (Equation 1).

$$
\varepsilon_{c r i t}=\frac{U C S}{E}
$$


It is good to remark that, in general, the critical strain $\varepsilon_{\text {crit }}$ is different to that at failure $\varepsilon_{\mathrm{p}}$ (Figure 1 ). However, Sakurai (1981) suggested that the critical strain may be used as the strain at failure because they present similar values for brittle materials. However, this critical strain needs to be corrected (Equation 2) to take account of the non-linearities of the constitutive model and thus to correctly represent the strain at failure $\varepsilon_{\text {failure }}$

$$
\varepsilon_{\text {failure }}=\frac{\varepsilon_{\text {crit }}}{1-R_{f}}
$$

Where $R_{f}$ is a parameter which represents the failure strength and varies from 0.05 and 0.8 , according to Sakurai (1981). Even though the choice of $R_{f}$ is made subjectively and, to the best of our knowledge, a method to estimate $R_{f}$ is not available in literature. This motivates our study on a new prediction method of the strain at failure.



Figure 1 Sakurai's idealisation of the stress-strain behaviour

\section{Methodology}

Given that in situ load tests on pillars (up to failure) are seldom found in literature (Yan-lin \& Wen 2014) and because they might be extremely dangerous and time and resource-consuming, the present study aims to analyse the mechanical response of pillars based on numerical modelling. A flexible numerical model of 1/8th of a single square pillar was implemented in FLAC3D v 5.01 (Itasca Consulting Group, Inc. 2012) using FISH programming (Figure 2). The latter routine was used as an implicit performance function to evaluate the pillar's strain at failure $\varepsilon_{p p}$ and peak vertical stress $\sigma_{p p}$. The strain at failure was measured as the ratio of the convergence between the roof and the floor (measured at the centroid of the section) to the pillar's initial height.
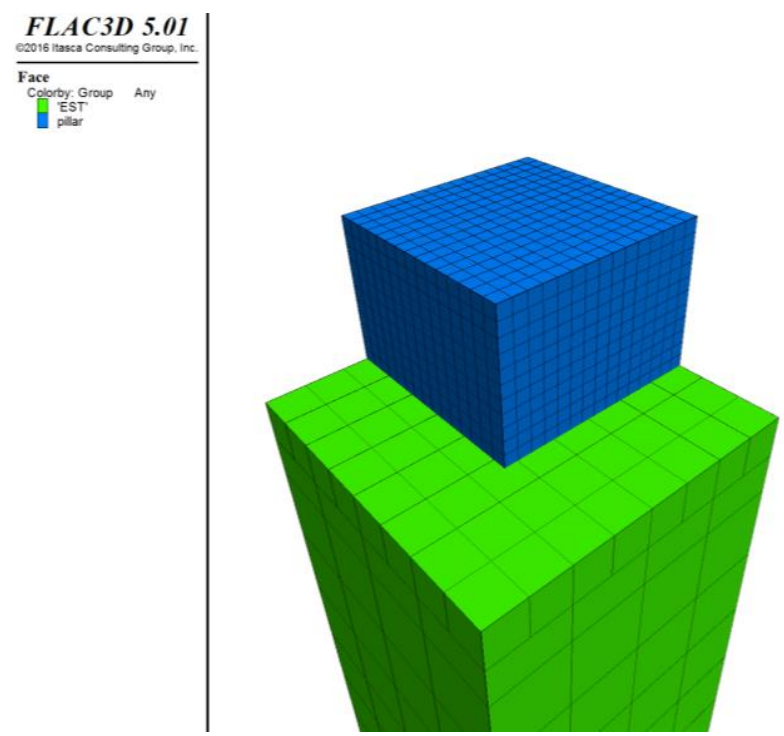

Figure 2 Example of the geometry of a numerical model of the pillar 
The pillar's rock mass was modelled using the generalised Hoek-Brown failure criterion with post-peak parameters described according to the Cai et al. (2007) and Ribacchi (2000) recommendations (path OEPST). The model parameters were calculated using FISH functions for peak and residual conditions, indicated by subscripts ' $p$ ' and ' $r$ ' respectively. The peak parameters were calculated according to Hoek et al. (2002). The post-peak behaviour was represented according to Ribacchi (2000) (Figure 3). A perfectly plastic peak differential stress $q_{p}$ is assumed from the critical deformation $\varepsilon_{e}$ to the peak deformation $\varepsilon_{p}$. After point $\mathrm{P}$, the rock mass experiences a progressive linear strain softening with a slope $\left|E_{n}\right|$ down to a residual differential stress $q_{r}$, reached at the final deformation $\varepsilon_{s}$. The peak deformation $\varepsilon_{p}$ was calculated based on typical values of the ratio $\left(\varepsilon_{p}-\varepsilon_{e}\right) / \varepsilon_{e}$ which was observed to vary between 0.3 and 0.7 (Ribacchi 2000). The final deformation $\varepsilon_{s}$ was estimated using the brittleness index $I_{B}=\left|E_{n}\right| / E_{O}$ which varies typically between 0.1 and 0.5 .

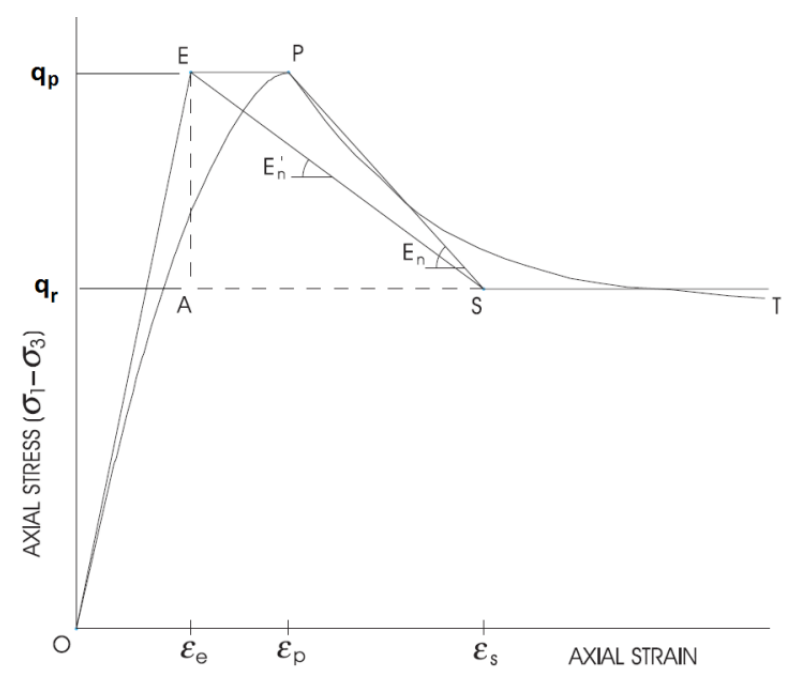

Figure 3 Brittle behaviour adopted for the rock mass (Ribacchi 2000)

The residual parameters were calculated using the residual GSI proposed by Cai et al. (2007) where GSI is obtained using Equation 3.

$$
\mathrm{GSI}_{\mathrm{r}}=\mathrm{GSI} \exp (-0.0134 \mathrm{GSI})
$$

Then, the residual strength parameters were calculated according to Hoek et al. (2002) using $\mathrm{GSI}_{r}, m_{i}$ and $D_{r}=0$. Other authors have discussed the residual value of the GSI recommending proportional constant reductions, such as Russo et al. (1998) which set the residual GSI to $36 \%$ of the peak value, and Ribacchi (2000) who recommended a residual value equivalent to $70 \%$ of the peak GSI. Cai's method was chosen because of its generality.

Additionally, the post-peak parameters were corrected to take into account the grid dependency of the results of the numerical model. This correction was done according to the user's manual of FLAC3D v6.0 (Itasca Consulting Group, Inc. 2017) where post-peak deformations are corrected by the multipliers $\lambda_{1}=(10-0.1 \mathrm{GSI}) / 3$ and $\lambda_{2}=R / 20(R$ is the number of zones for pillar edge). The denominator of the second multiplier needs a specific performance calibration, but here we used the same value of 20 used in the user's manual of FLAC3D v6.0.

The floor and roof's rock mass was modelled using an elastic-plastic generalised Hoek-Brown failure criterion which is stronger than the pillar's material to ensure that failure is induced in the pillar and not in the foundation or roof.

Once the properties were allocated to the model and the in situ stress state established, a numerical load test (NLT) was carried out to determine the peak vertical stress registered at the pillar's middle section and the corresponding peak strain. Figure 4 presents a typical output of an NLT. Finally, results were analysed in order to find tendencies, typical behaviours and/or correlations. 


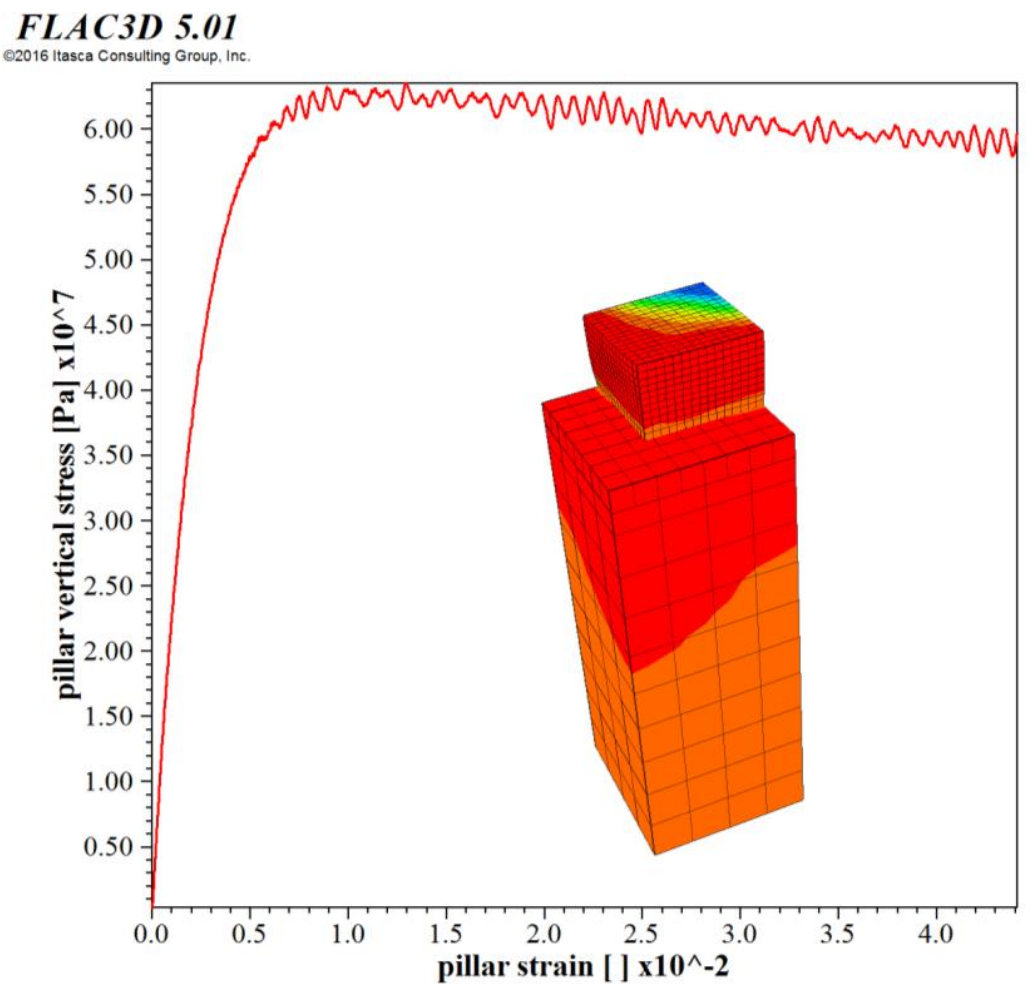

Figure 4 Example of the stress-strain curve registered in one of the numerical load tests

\section{Data}

In order to cover a wide range of scenarios, 320 NLTs were performed for a representative sampling space of the different variables involved in the estimation of the mechanical behaviour of pillars. Four parameters were varied: pillar length-to-height ratio $(\mathrm{w} / \mathrm{h})$, rock mass quality (GSI), intact rock strength (UCS) and the Hoek-Brown parameter mi. The remaining parameters were kept constant. Table 1 summarises the values and ranges of the main variables used in the NLTs. A MATLAB (The MathWorks Inc. 2016) routine was built to perform the automatic execution of several combinations of the input parameters.

Table 1 Values and ranges of the main variables used in the numerical load tests

\begin{tabular}{lll}
\hline Variable & Units & Values \\
\hline $\mathrm{w} / \mathrm{h}$ & - & $0.5-4.5$ \\
$\mathrm{GSI}$ & - & $30-90$ \\
$\sigma_{\mathrm{ci}}$ & $\mathrm{MPa}$ & $30-250$ \\
$\mathrm{~m}_{\mathrm{i}}$ & - & $5-35$ \\
$\mathrm{~h}$ & $\mathrm{~m}$ & 3.5 \\
$\mathrm{MR}$ & - & 500 \\
$\mathrm{D}$ & - & 0.0 \\
$\mathrm{D}_{\mathrm{r}}$ & - & 0.0 \\
$\left(\varepsilon_{\mathrm{p}}-\varepsilon_{\mathrm{e}}\right) / \varepsilon_{\mathrm{e}}$ & - & 0.7 \\
$\mathrm{I}_{\mathrm{B}}$ & - & 0.3 \\
\hline
\end{tabular}




\section{$4 \quad$ Results}

The peak vertical stress and critical strain at the pillar were plotted against the ratio $w / h$ and the rock mass strength $\sigma_{c m}$ (Figure 5). The rock mass strength was used instead of the UCS of the rock mass because the rock mass strength has less variability than the laboratory tests. The peak vertical stress exhibited values between 0.005 and 1,260 MPa, increasing quickly for small values of $w / h$ and then decelerating. Regarding the rock mass strength, the peak stress presented direct correlation from one time up to six times the rock mass strength. On the other hand, the critical strain presented maximum values of approximately $4.5 \%$ of the pillar height, which agreed with the critical strain values found by Sakurai (1981). The critical strain increased with $w / h$ but decreased with the rock mass strength. The latter might be explained by the brittle behaviour considered in the numerical model where competent rock masses are more brittle than weaker ones.

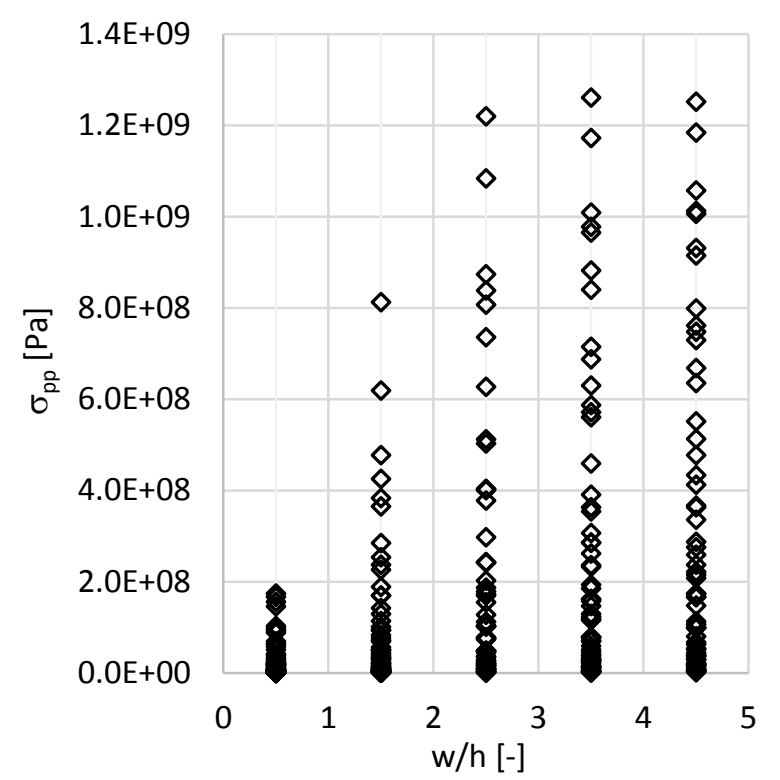

(a)

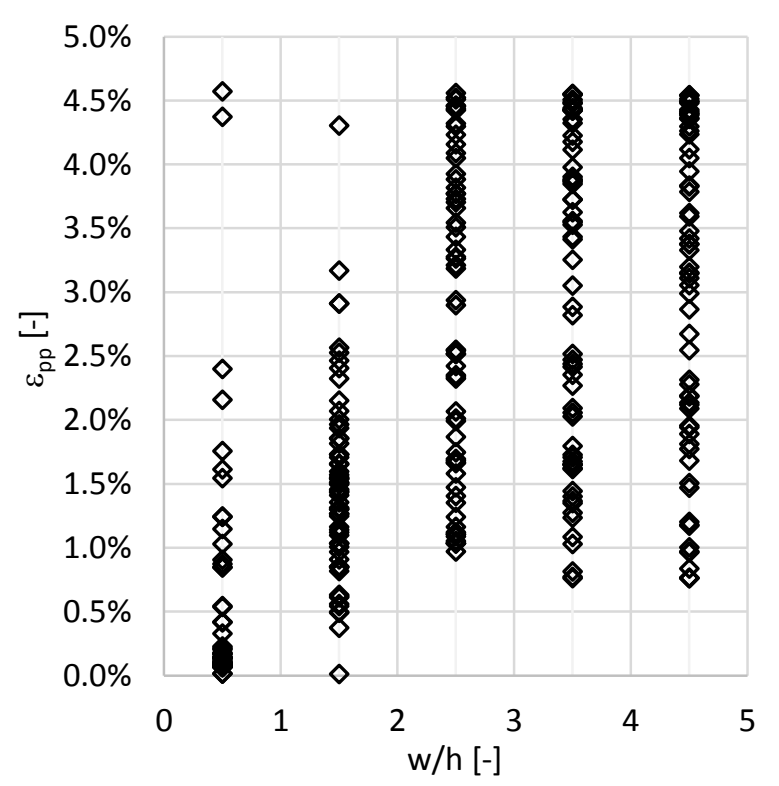

(c)

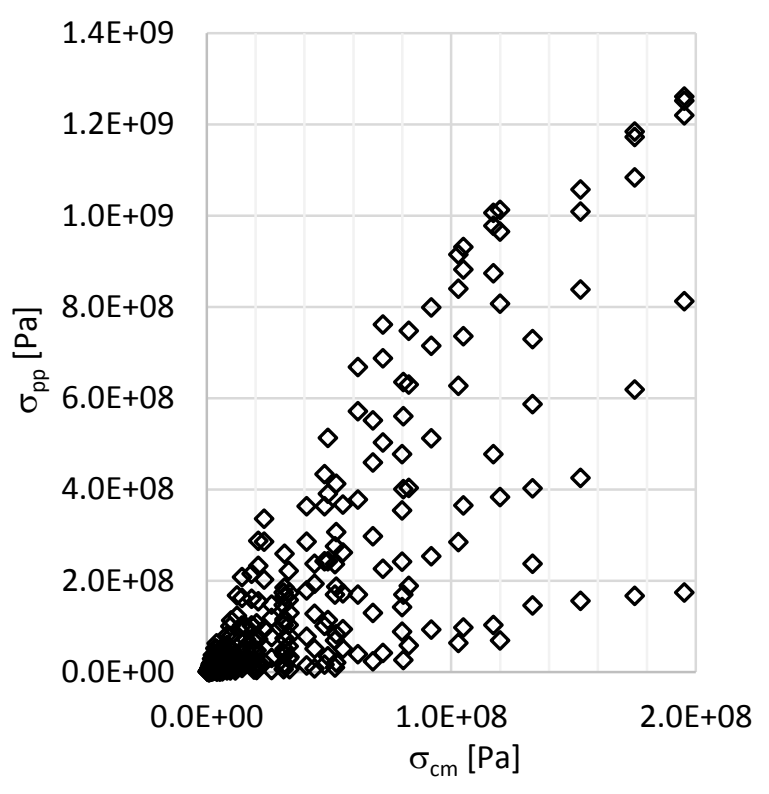

(b)

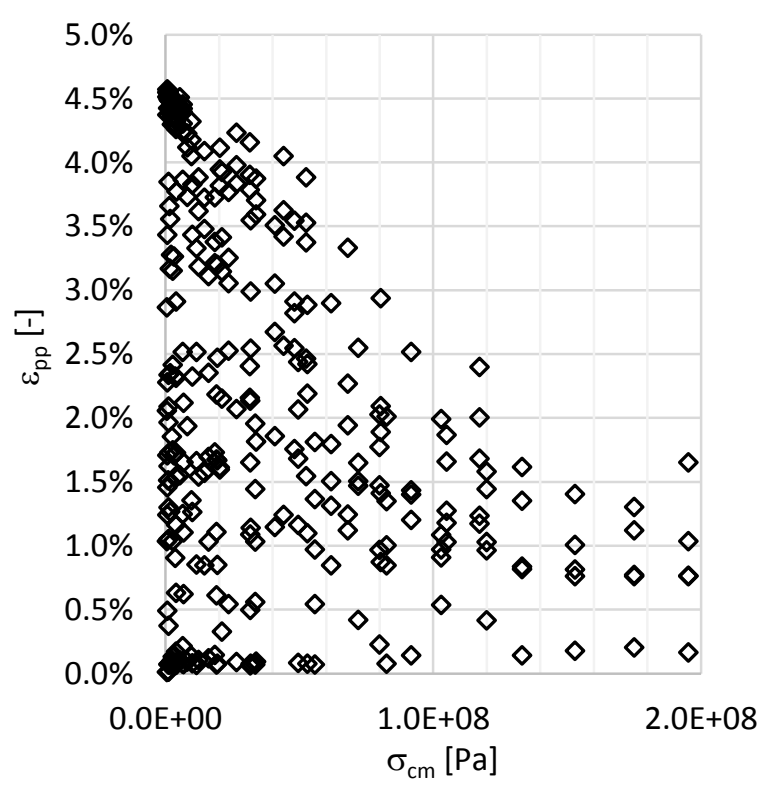

(d)

Figure 5 Critical strain and peak vertical stress of pillar against pillar slenderness and rock mass strength $\left(\sigma_{c m}\right)$ 
Peak stress was plotted against critical strain, and a large scatter was observed in the data presented in Figure 6 . The only noticeable characteristic is that there exists an inverse relation between them, e.g. large peak stresses tend to present small critical strains. The ratio is less than $1 \%$ for high peak stresses, and up to $4.5 \%$ for small peak stress values. The small peak stresses also have a larger scatter of critical strain values.

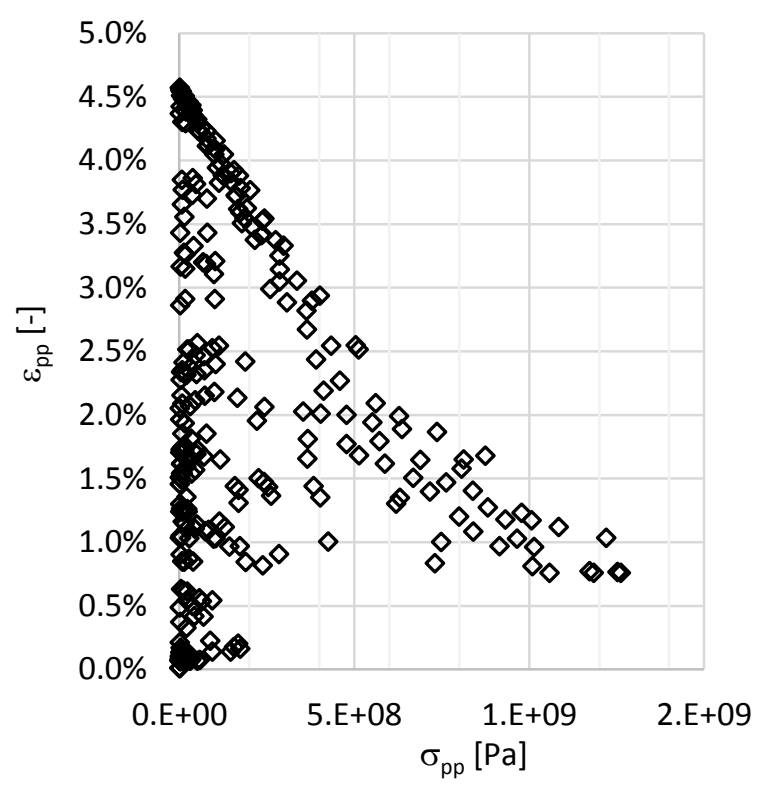

Figure 6 Critical strain versus peak vertical stress at pillar

Recalling Sakurai's critical strain (Equation 1), a correction factor is introduced to best predict the pillar's strain at failure in brittle rock masses.

$$
\varepsilon_{p p, f}=\varepsilon_{\text {crit }} f_{\text {strain }}
$$

The proposed correction factor is presented by the following formula:

$$
f_{\text {strain }}=\mathrm{a}+\mathrm{b}(\mathrm{w} / \mathrm{h})^{\mathrm{c}}
$$

where:

$a, b$ and $c$ are fitting parameters.

The fitting process was performed, conditioning that $\varepsilon_{p p, f}$ would reproduce and accurately forecast $\varepsilon_{p p}$. In other words, $\varepsilon_{p p, f}=\varepsilon_{p p}+$ error. Figure 7 presents the NLT correction factor $f_{\text {strain }}$ (Equation 6) and a linear approximation $f_{\text {strain-lin }}$ (Equation 7).

$$
\begin{gathered}
f_{\text {strain }}=0.139+5.089(\mathrm{w} / \mathrm{h})^{0.911} \\
f_{\text {strain-lin }}=0.933+4.332 \mathrm{w} / \mathrm{h}
\end{gathered}
$$

Substituting Equations 6 and 7 into Equation 4 yields the corrected failure strain prediction (Equations 8 and 9 respectively).

$$
\begin{gathered}
\varepsilon_{p p, f}=\left[0.139+5.089(\mathrm{w} / \mathrm{h})^{0.911}\right] \varepsilon_{c r i t} \\
\varepsilon_{p p, f}=[0.933+4.332 \mathrm{w} / \mathrm{h}] \varepsilon_{c r i t}
\end{gathered}
$$






Figure 7 Correction factor for critical strain at pillar

The plot of the predicted values of the critical strain (Figure 8) revealed that the current formulation tends to overestimate the critical values of the pillar's strains for larger values. A closer inspection into the overestimated values of critical strain reveals that this overestimation occurs for competent rock masses. Again, this might be explained by the fact that competent rock masses suffer a higher strength reduction towards the residual strength. Hence, the current formulation must be used with caution for large values of the predicted critical strain $\left(\varepsilon_{p p, f}>5 \%\right)$.

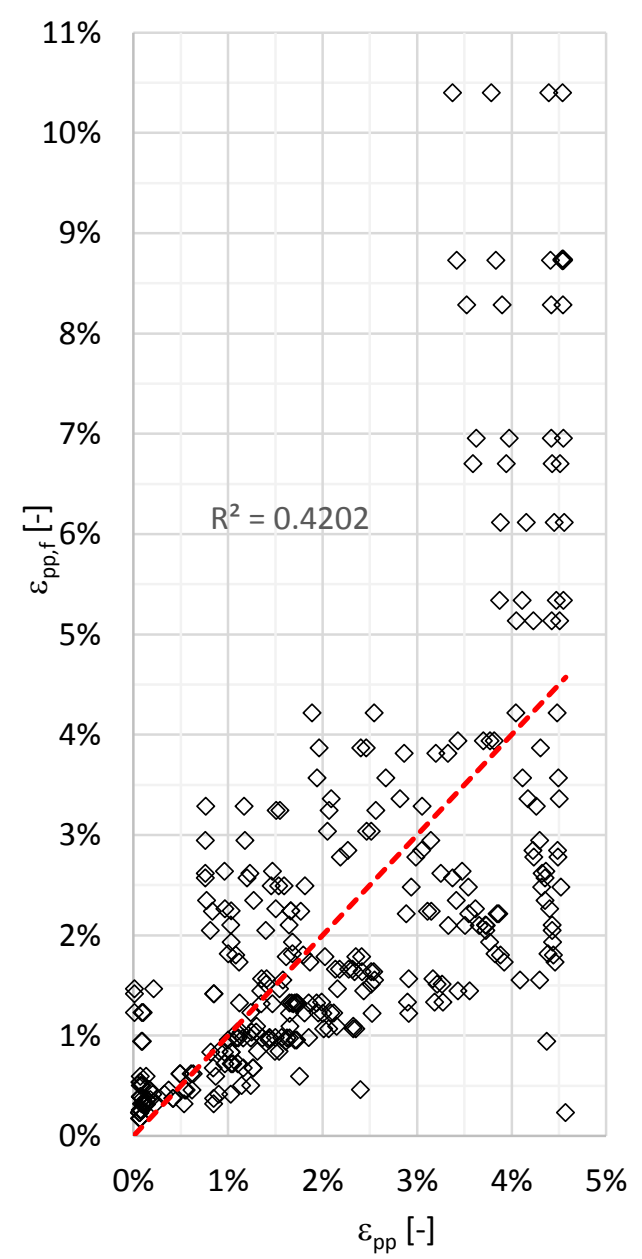

Figure 8 Modelled critical strain (Equation 8) versus measured critical strain at NLT 
Regarding the values of the correction factor obtained in this study, they varied between two and 20 for width-to-height ratios of 0.3 and 4.5 , respectively. At this point, it is good to remark that the correction factor recommended by Sakurai (Equation 2) presents values ranging from 1.1 and 5.0 for $R_{f}$ of 0.05 and 0.8 , respectively. Sakurai's values are contained in the range of values obtained in this study because we considered a larger range of width-to-height ratios than Sakurai. Sakurai's values correspond to standard laboratory specimens' width-to-height ratios smaller than 0.5 , and UCS and confining stress of up to $100 \mathrm{MPa}$ and $100 \mathrm{MPa}$ respectively. The present study covered a wider range of width-to-height ratios and rock mass strengths. Also, as stated by Hoek and Brown (1997), the rock mass strength is more suitable for pillar design.

\section{Conclusion}

This paper presented a study on the possibility of improving Sakurai's critical strain evaluation technique. The results obtained from the numerical models presented a large scatter and this was reflected in the difficulty of finding a suitable correlation among the variables that were considered in the modelling process. However, a correction of the classical critical strain criterion is proposed in Equation 8. Alternatively, a best fit linear version is presented in Equation 9. It is worth noting that the presented correction still presents some degree of variability, but does improve the accuracy when evaluating the limit state of pillars.

\section{Acknowledgement}

The authors are grateful for the financial support of the Instituto Tecnológico Vale.

\section{References}

Aydan, O, Akagi, T \& Kawamoto, T 1993, 'A method for the prediction of the squeezing potential of rock around tunnels', Assessment and Prevention of Failure Phenomena in Rock Engineering, A.A. Balkema, Rotterdam, pp. 767-774.

Bullock, RL 2011, 'Room-and-pillar mining in hard rock', in P Darling (ed.), SME Mining Engineering Handbook, 3rd edn, Society for Mining, Metallurgy, and Exploration, Englewood, pp. 1327-1338.

Cai, M, Kaiser, PK, Tasaka, Y \& Minami, M 2007, 'Determination of residual strength parameters of jointed rock masses using the GSI system', International Journal of Rock Mechanics \& Mining Sciences, vol. 44, pp. 247-265.

Corkum, AG \& Board, MP 2016, 'Numerical analysis of longwall mining layout at Solvay Mine, Wyoming', International Journal of Rock Mechanics \& Mining Sciences, vol. 89, pp. 94-108.

Deng, J, Yue, ZQ, Tham, LG \& Zhu, HH 2003, 'Pillar design by combining finite element methods, neural networks and reliability: A case study of the Feng Huangshan copper mine, China', International Journal of Rock Mechanics and Mining Sciences, vol. 40, no. 4, pp. 585-599.

Gao, W \& Mingming, G 2016, 'Stability of a coal pillar for strip mining based on an elastic-plastic analysis', International Journal of Rock Mechanics and Mining Sciences, vol. 87, pp. 23-28.

Hoek, E \& Brown, ET 1997, 'Practical estimates of rock mass strength', International Journal of Rock Mechanics and Mining, vol. 34, no. 8, pp. 1165-1186.

Hoek, E, Carlos C-T \& Corkum, B 2002, 'Hoek-Brown failure criterion - 2002 edition', in R Hammah (ed.), Proceedings of the 5th North American Rock Mechanics Symposium and the 17th Tunnelling Association of Canada Conference, University of Toronto Press, Toronto, pp. 267-273.

Idris, MA, Saiang, D \& Nordlund, E 2015, 'Stochastic assessment of pillar stability at Laisvall mine using artificial neural network', Tunnelling and Underground Space Technology, vol. 49, pp. 307-319.

Itasca Consulting Group, Inc. 2012, FLAC3D, version 5.01, Itasca Consulting Group, Inc., Minneapolis.

Itasca Consulting Group, Inc. 2017, FLAC3D Version 6 User's Manual, Itasca Consulting Group, Inc., Minneapolis.

Jaiswal, A \& Shrivastva, BK 2009, 'Numerical simulation of coal pillar strength', International Journal of Rock Mechanics and Mining Sciences, vol. 46, no. 4, pp. 779-788.

Kortnik, J 2009, 'Optimization of the high safety pillars for the underground excavation of natural stone blocks', Acta Geotechnica Slovenica, vol. 6, no. 1, pp. 35-48.

Laubscher, DH 1990, 'A geomechanics classification system for the rating of rock mass in mine design', Journal of the South African Institute of Mining and Metallurgy, vol. 90, no. 10, pp. 257-273

Lunder, PJ \& Pakalnis, RC 1997, 'A determination of the strength of hard-rock mine pillars', CIM Bulletin, vol. 90, no. 1014

Navarro Torres, VF, Da Gama, CD, Costa E Silva, M, Falcão Neves, P \& Xie, Q 2011, 'Comparative stability analyses of traditional and selective room-and-pillar mining techniques for sub-horizontal tungsten veins', International Journal of Minerals, Metallurgy and Materials, vol. 18, no. 1, pp. 1-8. 
Obert, L \& Duvall, WI 1967, Rock Mechanics and the Design of Structures in Rock, John Wiley \& Sons, Hoboken.

Pariseau, WG \& Eitani, IM 1981, 'Comparisons between finite element calculations and field measurements of room closure and pillar stress during retreat mining', International Journal of Rock Mechanics and Mining Sciences, vol. 18, no. 4, pp. 305319.

Ribacchi, R 2000, 'Mechanical tests on pervasively jointed rock material: Insight into rock mass behaviour', Rock Mechanics and Rock Engineering, vol. 33, no. 4, pp. 243-266.

Russo, G, Kalamaras, GS \& Grasso, P 1998, 'A discussion on the concepts of geomechanical classes behavior categories and technical classes for an underground project', Gallerie E Grandi Opere Sotterranee, vol. 54, pp. 40-51.

Sakurai, S 1981, 'Direct strain evaluation technique in construction of underground opening', Proceedings of the 22nd US Symposium on Rock Mechanics, American Rock Mechanics Association, Alexandria, pp. 278-282.

Sakurai, S 1997, 'Strength parameters of rocks determined from back analysis of measured displacements', Proceedings of the First Asian Rock Mechanics Symposium, International Society for Rock Mechanics, Lisbon.

Sakurai, S 1999, 'Interpretation of field measurements in tunneling practice', Proceedings of the 9th ISRM Congress, International Society for Rock Mechanics, Lisbon, pp. 1517-1523.

Sakurai, S, Kawashima, I \& Otani, T 1993, 'A criterion for assessing the stability of tunnels', in L Ribeiro, E Sousa \& NF Grossman (eds), Proceedings of the ISRM International Symposium: EUROCK '93, vol.2, A.A. Balkema, Rotterdam, pp. 929-973.

The MathWorks Inc. 2016, MATLAB, version R2016a, The MathWorks Inc., Natick, viewed 20 July 2017, https://au.mathworks.com/ products/new_products/release2016a.html

Yan-lin, Z \& Wen, W 2014, 'Thickness reduction method of the pillar size set safely and its application', Electronic Journal of Geotechnical Engineering, vol. 19, no. Z6, pp. 18291-18304. 
